\title{
BAD EGGS AND BABIES; IS H2S A KEY PLAYER IN THE NEWBORN CIRCULATION?
}

\author{
R.M. Dyson ${ }^{1,2}$, H.K. Palliser ${ }^{1,3}$, I.M. Wright ${ }^{1,2}$
}

${ }^{1}$ Mothers \& Babies Research Centre, Hunter Medical Research Institute, ${ }^{2}$ Discipline of Paediatrics \& Child Health, ${ }^{3}$ School of Biomedical Sciences \& Pharmacy, University of Newcastle, Newcastle, NSW, Australia

Background and aims: Previously we have shown that microvascular dysfunction is associated with illness severity in premature infants. Hydrogen sulphide $\left(\mathrm{H}_{2} \mathrm{~S}\right)$ is a gasotransmitter that functions as a vascular mediator in vitro and there is evidence in adult studies suggesting a possible role in regulation of microvascular tone. Nothing is known about the role of $\mathrm{H}_{2} \mathrm{~S}$ in the transitional circulation of the newborn. Nitric oxide and carbon monoxide (other gasotransmitters) have already been shown to play a crucial role at this time and so it was hypothesised that $\mathrm{H}_{2} \mathrm{~S}$ may also contribute to regulation of microvascular tone during this time.

Methods: $\mathrm{H}_{2} \mathrm{~S}$ is present in very low concentrations within the microcirculation and is cleared by exhalation or converted to a stable metabolite, thiosulphate, which is excreted in urine. $24 \mathrm{hr}$ urine samples from the first day of life were assayed for thiosulphate using a modification of the Sorbo spectrophotometric method as a marker of total body turnover of $\mathrm{H}_{2} \mathrm{~S}$. Results were tested by one-way ANOVA with posthoc testing. All values are mean \pm SEM.

Results: Urinary thiosulphate concentrations were significantly higher in very premature neonates $0.29 \pm 0.03 \mu \mathrm{mol} / \mathrm{ml}(\mathrm{n}=13 ; \leq 28$ weeks completed gestation) than preterm neonates born at later gestational ages $0.13 \pm 0.02 \mu \mathrm{mol} / \mathrm{ml}(\mathrm{n}=11 ; \mathrm{p}<0.001)$ or term neonates $0.09 \pm 0.039 \mu \mathrm{mol} / \mathrm{ml}(\mathrm{n}=11 ; \mathrm{p}<0.001)$.

Conclusions: This is the first evidence that $\mathrm{H}_{2} \mathrm{~S}$ may play a significant role in the control of microvascular tone in the transitional circulation of the neonate. Further investigation to verify this is underway and opens new therapeutic possibilities in this vulnerable group. 